\title{
Gamification as a Sustainable Tool for HR Managers
}

\author{
Anuj Kumar, T. Sowdamini, Sanjay Manocha, Purvi Pujari
}

\begin{abstract}
The competition in the business field is increasing continuously. The COVID-19 pandemic brings more challenges for organizations. The human resource managers in the organizations face challenges of retention of employees, maintaining mental peace, handling anxiety, fulfilling job demands, and handling the motivation level of the employees. Daily new challenges are coming to the surface. Creativity and innovation have been the need of the hour for since long. COVID-19 pandemic is demanding more creativity and innovations from the organizations and their HR managers. A detailed literature review has been done by taking into cognizance various aspects of gamification as applicable to the Human Resource domain. The objectives of this research are to understand the role of creativity and innovation in the organization's success and identify HR managers' problems during Covid-19. The third and fourth objectives of the paper were to study gamification and its application in various $H R$ functions and to determine how gamification can help achieve sustainable practices in the organizations this paper; the researchers have discussed gamification as a creative and innovative tool that can help human resource managers in dealing with various challenges and help them to achieve the goals of sustainability.
\end{abstract}

Keywords: Gamification, COVID-19, Human Resource, Innovation, Creativity, Sustainability

JEL Codes: M12, Q01, M50

\section{Introduction}

"Innovation and Creativity are the different factors between a leader and a follower. They act as differentiators." Innovation and creativity are two crucial skills that have been recognized as the pure path to success for organizations, be it small or big. Every organization needs a differentiator to succeed in this competitive and dynamic era. To reach the heights and achieve goals, proper planning in the right direction is necessary. Certain things which have been the core factors of success in an organization need to be modified or even replaced if the situation demands. Satisfying stakeholders, one of the critical roles of organizations, can be ensured smoothly by a proper understanding of the relevance of Innovation and Creativity by the management. The process of innovation caters to the creation and implementation of new and novel ideas. It screens the good views from the pool and converts them into commercial and feasible products and services. It includes products and even processes that make things better and easier for the organization and society too. Creativity can be called the driving force behind innovation, which provides a different perspective and independence from the rigid restrictions from the rules and norms laid down by the authorities. Innovation and creativity are complementary to each other; they go hand in hand. Without Innovation, Creativity is of no use. Creativity provides the ability to produce new ideas for the improvement and betterment

\footnotetext{
Mr. Anuj Kumar, Assistant Professor, Apeejay School of Management, Dwarka, Delhi, India e-mail: profanuj15@gmail.com

Dr. T. Sowdamini , Assistant Professor, Gitam Institute of Management, GITAM, Visakhapatnam, Andhra Pradesh, India, e-mail: sthatta@gitam.edu

Dr. Sanjay Manocha, Assistant Professor, Bharati Vidyapeeth Institute of Management and Research, New Delhi, India, e-mail: drsanjaymanocha@gmail.com

Dr. Purvi Pujari, Associate Professor, Bharati Vidyapeeth Institute of Management Studies and Research, Navi

Mumbai, India, e-mail: purvipujari@gmail.com

DOI 10.32725/acta.2021.003

(C) Copyright by Faculty of Economics, University of South Bohemia in České Budějovice
} 
of quality. However, having creative ideas does not guarantee success if they are not put into action; this is done by innovation.

\section{Research objectives}

To understand the role of creativity and innovation in the organization success

To study gamification and its application in various HR functions

To identify HR managers problems during Covid-19

To identify how gamification helps for sustainable practices

\section{Research Gap}

A detailed review of the literature in this field by the researchers implies that minimal work in sustainability applies to HR using gamification as a tool. The significance of gamification as an HR tool for enhancing productivity through improving mental health and behavioral issues and, in turn, bringing creative, sustainable solutions to the organization needs to be investigated.

\section{"Winners don't do different things; they do things differently."}

In the last few decades, the problem-solving process has changed drastically in organizations. Finding solutions to the hurdles requires creative insights by the employees and not the old monotonous manuals followed for centuries. There has been a substantial change in the thought process with globalization and modernization, which requires innovation accompanied by creativity as a prerequisite.

\section{Importance of Creativity and Innovation in Organizations}

A critical reexamination of the things which have been painstakingly built and have served the organizations well over time is a painful task for the management. Thus, most of the time, adopting the innovative and creative approach does not go well with the stakeholders (Christensen, 1997). There have been various research studies that prove the importance of Creativity and Innovation in organizations. They are the building forces to attract prosperity. The productivity can be surged by exploring unknown territories and diving into oceans of new creative proposals. It not only helps in the entity's budget but also acts as a problem solver and leads to a boost in the market share. Competitive edge and creative problem solving are the keys to triumph. It not only provides for the development of innovative strategies but also earns goodwill and a reputation for the firm. Organizational creativity must be backed by individual creativity. Individual Creativity and corporate Innovation are inextricably linked. The findings of a survey by Forrester imply that $82 \%$ of executives agree that invention provides a route to success. Innovation and creativity are crucial for the organization's growth, especially when firms must have their way out from a highly competitive and dynamic world. The global environment that organizations must face nowadays makes Creativity and Innovation a core part of their functional areas. This requires challenging the thought process of the employees, which leads to new business avenues and opportunities.

Senior management needs to be clear on their priority list regarding factors necessary for the achievement of goals. According to a survey conducted by IBM, more than 1500 CEOs ranked innovation as the most crucial element for business growth. This explains their importance as it leaves even management discipline, vision, and integrity behind. Creativity helps to build experiences. This is the era of experiences. People visit Starbucks not just for the coffee, but the ambiance, the personalization, and the enriched experience they always cherish in their memories. The innovation model paves the way to open feedback and suggestions from all the stakeholders, bringing fresh perspectives and ideas, resulting in better products and satisfied customers. Creativity provides direction for obtaining proposals for better conflict management 
and environmental analysis. The new idea generation process is not limited to the managerial personnel but also factory workers and other stakeholders. For this, organizations create a psychologically safe environment assuring the personnel that there will not be any humiliation or punishments for voicing their ideas and concerns, even if they are wrong. Innovation and creativity are not limited to the artistic and creative fields. Management is an art and a science. Innovation and creativity are the need of the hour in all the spheres of life. For rewarding and pleasantly surprising outcomes, implementing new ideas is a must.

\section{Problems for Human Resource Manager's amidst COVID 19 scenario}

The last month of the previous year has been devastating for the human population on earth. Several cases of humans affected by the pandemic disease have been reported across the globe. Many countries of the world have been observing lockdown government and apex health bodies asking people to stay at home observe a break from commercial work activities due to the threat of becoming victims of virus spread disease and this virus with which human body is not able to fight named as coronavirus. Coronavirus is a strain of viruses common in animals like bats, camels, cattle, pangolins, and this virus gets transferred to the human body, causing disease as COVID 19. Cases of humans suffering from COVID 19 disease are reported from Wuhan city of China, where a prevalent seafood and animal market. As of now, it is not confirmed how the coronavirus reached humans first. World Health Organization (WHO), a unit of the United Nations constituted to safeguard international public health, declared coronavirus spread disease as pandemic on 11 March 2020, as people getting this virus-caused disease are not immune-competent (Ramesh, 2020). Mental and physical strain in employees due to the pandemic, new supervision challenges, increased job demands, and burnout are some of the commonly stated issues to HR (Kniffin et al., 2021). Risk of contagion and stigma, social exclusion, and anxiety among the employees have been identified as the main issues faced by HR. (Hamouche, 2020). One more study by McQuire et al. pointed out that post-COVID-19, it is essential to care for employees' psychological health and well-being. An ethics of care approach should be adopted to ensure better HR practices (McGuire, 2021).

COVID 19 is becoming a novel disruptor to human activities. The new normal in the present pandemic-affected world will be work from home for corporate employees and children studying at home on virtual platforms. Companies are devising ways to develop a skill set in their employees as they will perform many of the company operations from remote locations. Work from home guidelines have been prepared by Microsoft and shared with its global workforce. This guidelines document is also available on the Microsoft website for its customers who can use it for their respective companies. This work from home guide mentions the culture or habits people can adopt in managing their office and household work along with self-care. The new normal will look for candidates with some skills instead of only degrees (Kumar et al., 2021; Kumar \& Ayedee, 2021). As per one of the senior officials, the future will be of machines replacing men's work of problem-solving devoted to problem finding instead. The new normal of working will find learning opportunities online, forcing companies to launch the radical transformation of corporate learning. Wal-Mart, an American multinational retail corporation, has partnered with Strive, a virtual reality training company, to guide its workforce to better deal with Black Friday in-store shopping. Best Western Hotels has partnered with Mursion, a virtual reality training company, to develop the problem-solving skills of its employees. Home Depot has prepared a mobile application for the training of its new hires. Companies human resource managers of companies will be using more gamification and virtual reality to engage their employees (Meister, 2020). 


\section{Methods}

Companies are adopting various cost minimization solutions to deal with current COVID 19 pandemic situations where the world is indoors. There is a suspension of industrial operations resulting in a negative impact on the economy. The retail, tourism, hospitality, cinema, and travel sectors are affected the most, and companies like Scandinavian Airlines adopted furlough leaves for 80 percent of employees. The largest hotel chain Marriott International also chose this solution and asked thousands of its employees to go on leave without pay (Deol, 2020). The human resource managers are facing challenges of devising new working models, compensation restructuring, developing online learning skills of employees, shutting down their more minor or non-performing divisions or branches, boosting the morale of the employees, managing temporary or contractual employees ensuring no damage to the popularity and reputation build by the company over a period. Companies may be adopting furlough leaves wherein employees are being asked to go on mandatory leave without pay. They will be brought back to business depending upon its profit sustainability in the future. Every HR measure should comply with legal requirements, the well-being of employees with profit maximization of the company (Agarwal, 2020).

Table 1 HR issues during COVID-19

\begin{tabular}{|l|l|l|}
\hline S. No. & \multicolumn{1}{|c|}{ Authors } & \multicolumn{1}{|c|}{ HR issues during COVID-19 } \\
\hline $\mathbf{2}$ & (Kniffin, 2021) & $\begin{array}{l}\text { The researchers have identified mental and } \\
\text { physical strain in employees, challenges of } \\
\text { supervision, increased job demands, burnout, } \\
\text { deviant behavior, and withdrawal. }\end{array}$ \\
\hline $\mathbf{3 .}$ & (Ashraf Saeed Elsafty, 2020) & $\begin{array}{l}\text { The paper discussed in depth the issues related } \\
\text { to COVID-19 related to the retention of } \\
\text { employees. It inferred that better communication } \\
\text { with employees that helps in improving retention } \\
\text { issues in an organization. }\end{array}$ \\
\hline $\mathbf{4 .}$ & (Hamouche, 2020) & $\begin{array}{l}\text { The authors have identified the moderators and } \\
\text { stressors as a result of the Coronavirus } \\
\text { pandemic. Risk of contagion and stigma, social } \\
\text { exclusion, and anxiety among the employees } \\
\text { have been identified as the main issues faced by } \\
\text { HR. }\end{array}$ \\
\hline $\mathbf{5}$ & (Majzun, 2020) & $\begin{array}{l}\text { This research highlighted the role pressures and } \\
\text { work-family contradictions during COVID } \\
\text { times. It also emphasizes the diminishing role of } \\
\text { person-environment fit during pandemic times. }\end{array}$ \\
\hline
\end{tabular}




\begin{tabular}{|l|l|l|}
\hline 6 & (McGuire, 2021) & $\begin{array}{l}\text { The research pointed out that post-COVID-19, it } \\
\text { is essential to care for employees' psychological } \\
\text { health and well-being. An ethics of care } \\
\text { approach should be adopted to ensure better HR } \\
\text { practices. }\end{array}$ \\
\hline
\end{tabular}

(Authors' own)

COVID 19 has disrupted the various industrial sectors of the global economy, especially hospitality, transportation travel, and tourism (Shaikh et al., 2021). Many of the companies now are suspending their hiring plans. At the same time, industrial sectors like healthcare, ecommerce are getting a surge in their business, so looking for new hires safely and effectively (Ayedee et al., 2021). Big companies like Amazon and Wal-Mart have exponentially increased their hiring endeavors as demand to cater increased demand of its offerings worldwide. The recruitment problem which HR managers are facing is of onboarding of new hires. These people are the ones who have been selected for the job but have yet to join due to the current crisis. Companies are trying to keep their present employees happy, encouraging them to work from home, and they've minimized efforts to attract new talent. In recruitment also companies are now finding themselves dependent on technology as remote video interviews, online campus drives are becoming the new recruitment normal. Thus, investing in recruitment automation tools and software will be gaining momentum in online recruiting. HR managers can use this time to do social responsibility activities like partnering with local citizens or organizations or the government in offering help to needy people. Companies need to be creative and innovative in creating a corporate culture of interactive communication with employees, customers, and other stakeholders heading towards finding creative ways to engage the whole company (Talview, 2020).

\section{What is gamification?}

Gamification is now a buzzword across businesses and industries. It mainly uses game theory and game designing to digitally interact with the workers or realize the target. At present, most companies are using these gaming modules to enhance customers' and employees' interest in a brand. During this competitive environment, gamification will make the corporate a differentiator within the market. More significantly than seventy percent of the "Forbes Global 2000 organizations" (Law, 2018) will be having at least one application based on gaming. Gamification does not associate with games, but it incorporates the essence of gaming to make workers tougher at their everyday jobs and reward them accordingly. As the workforce in various Industries is seemingly overtaken by millennials, it is a challenging errand for the HR managers to engross them correctly because millennials always search for innovative and exciting ways to engage themselves at their workplace. So, one such technique is Gamification companies are adapting to various areas.

\section{Variation between Gamification and Game-Based Learning}

Gamification and Game-Based Learning are often used fungible. Still, both have diverged in meaning (Lawande et al., 2016) as the previous is centered on game elements in non-game-like situations. In contrast, the latter uses actual gaming methodology to widen the learning experience. Hence the result differs as they vary in application.

\section{How does gamification work}

Gamification makes use of the cutthroat trait that is imbibed within us. If somebody is playing a game, they are so occupied and engrossed in that and sometimes even try to take the extra step in winning the game by which they achieve a superior sense of satisfaction. In a positive 
sense, these people can make the right decisions, employ the right people, or even aid other staff in achieving their goals. In the long run, gamification can boost employee engagement. Gamification has also been known to improve the performance of disengaged employees and improve commitment and enhance productive communication (Saha \& Pandita, 2017). Various researches have concluded that gamification increases retention and intrinsic motivation in employees (Simpson, 2015). It also aids in improving the effectiveness of employees by creating appraisal and feedback systems (Walls, 2021).

\section{Gains from gamification}

Cognitive development: Brain games help formulate and brain development. So mental growth of an employee improves thinking and analytical skills.

$>$ Increases in the level of engagement: The researchers uncovered that a game-like environment was beneficial to increase the productivity

$>$ The motivation for employees: Staff can fix personal targets and work on that which makes them inspire to reach their goals. Gamification also makes available individual progress reports.

$>$ It helps managers with performance tracking: Gamification apps/techniques are accommodative for managers to appraise employee performance on a real-time basis and have precise and unbiased information.

Table 2 Literature review on gamification

\begin{tabular}{|l|l|l|}
\hline S. No. & Authors & Gamification Approaches \\
\hline 1 & (Ferreira A.T., 2017) & $\begin{array}{l}\text { The researchers have done a systematic } \\
\text { review of 35 articles. He found that there has } \\
\text { been limited research on gamification in the } \\
\text { workplace, but studies with small samples } \\
\text { show positive results on the work } \\
\text { environment. }\end{array}$ \\
\hline 2 & (Saha, 2017) & $\begin{array}{l}\text { The authors state that gamification improves } \\
\text { the performance of disengaged employees' } \\
\text { performance, improves commitment, and } \\
\text { enhances productive communication. } \\
\text { Disadvantaged, which this result has pointed } \\
\text { out, is high cost with the uncertainty of the } \\
\text { impact on employee performance. }\end{array}$ \\
\hline 3 & $\begin{array}{l}\text { The research emphasized that there has been } \\
\text { a positive impact of gamification on } \\
\text { employee job satisfaction and no effect on } \\
\text { team building and internal communication. }\end{array}$ \\
\hline 4 & $\begin{array}{l}\text { The research states that gamification is an } \\
\text { attractive tool that can be used by human } \\
\text { resource managers for induction, learning \& } \\
\text { development, training, etc. It will improve } \\
\text { employees' engagement in the organizations. }\end{array}$ \\
\hline 5 & $\begin{array}{l}\text { Authors argue that gamification helps in } \\
\text { improving the effectiveness of employees by } \\
\text { creating appraisal and feedback systems. }\end{array}$ \\
\hline
\end{tabular}

(Authors' own) 


\section{Gamification as a tool for HR Managers}

Gamification in HR is a new concept applied in the organization on employees (Zoe, 2019). In late 2010, the usage of the term gamification was started and had its foundation of utilizing the elements and designs of gaming in things that are not related to gaming, too, to achieve employee engagement and motivation among the employees. Implementation of gaming in HR can draw a diversified workforce to the company. At the same time, it can also bring changes in training \& development, performance management. Further, gamification will also aid in amplifying the employer branding. It will also help the employees to align their aspirations with the business vision to perform well and to be more competitive by embracing various fun involved tasks at their jobs (Staff Writer, 2017) Gamification is an essential means in the current scenario, which plays a vital role in creating a pleasing experience for the users. The users can learn a lot while enjoying the game, which also increases the retention rate in the organizations. Given this, multiple firms have introduced gamification in the onboarding process, which will help employees to gel with new hires. Still, some entities are utilizing gamification as a tool to stimulate their employees to try out different organizational goals and see which ones they find appropriate. There are several ways of using Gamification in HR. It may serve as a model for HR in using gamification to attract, induct, train (learn), and develop, employ, and retain staff. The possibilities for applying Gamification to HR extend well beyond those that we listed here and HR experts who comprehend gamification to help develop gamification strategies.

\section{Gamification in recruitment and selection}

One of the quintessential duties of HR in the business enterprise is recruitment and selection. In the latest instances, the majority of the groups are going for an internet-based recruitment process. So, the majority of the potential employees are utilizing the companies recruitment websites. To get pick the proper candidates from the pool, personnel of HR wants to comprehend the system of online selection. For this motive, they want to replace the organization's internet site to entice the talent. A practical recruitment approach was continually an aggressive benefit for the entity (Nenadić, 2019) because multiple entities are looking for innovative employees.

Gamification is a trendy, contemporary, and innovative idea that attracts probable candidates. Gamification, coined aptly as 'RECRUITAINMENT,' permits aspirants to experience the recruitment method via quizzes, digital enterprise challenges, gamified quests associated with the company, and behavioral tests. To differentiate between gamified and game sourced evaluations is essential since the gamified evaluations are primarily concerned with psychological measurements which improve the employee commitment, and game-based assessment evaluates person conduct while enjoying the game. (Kirsten, 2019).

\section{Gamification in the measurement of recruitment can be}

$\checkmark$ A fresh and appealing employer brand helping to attract top talent

$\checkmark$ It reduces dropout rates helping to control recruitment costs.

$\checkmark$ Simplify the monotonous process of a job application and enclose it in a fun and attractive activity

Online Facebook games developed by Marriott, PWC, Siemens, and Google are full-size companies that use gamification, not for fun but the current recruiting process. It is entirely political (Eleni, 2019). Those companies have recognized two significant facts, firstly, most of their newest recruits are millennials, and secondly, they are likely to be gamers. At any or all stages of the recruiting process, gamification may provide touchpoints. Domino's encourage people to participate in their game "Domino's Pizza Mogul'" which familiarizes the brand among the people in the game who will make their pizza and win badges and money each time 
it is marketed. Further, this will draw the attention of the fresh candidates to want to work with a creative, ground-breaking, and fun team. "Brandstorm" is the talent-spotting tool vide which L'Oréal is influencing the new talent, apart from other devices such as 'R U HR?' and 'REVEAL.'

\section{Gamification in training and development}

Employees are frequently now not interested in training sessions (Baxter, 2016) due to negative appreciation of standards or lack of interest, leading to much less inside control on personnel to tackle these entities comprising gaming ideas into their education modules. So the use of gamification in coaching and improvement helps personnel become more excellent experts and chance takers. It additionally helps them enhance management skills.

Deloitte Leadership Academy is an online community imparting a massive quantity of coursework on a vast range of consultant subjects. The goal is to get coaching and open offerings for senior executives. Badgeville, with the valuable resource of Deloitte Game Mechanics, integrates gamified factors such as leader boards, rating symbols, and badges. With these practices, the personnel getting to know and additionally retention has increased.

\section{Gamification in employee engagement}

The engagement of personnel brings out several advantages to the enterprise. Employee hiring is a mechanism that may be used in the Organization (Saha \& Pandita, 2017), so the intelligence is amply deployed and efficiently harnessed. It helps to build up worker involvement and guide them to function in their roles better. Further, it interprets Innovation and Creativity in the employee's functioning. The crucial component in worker engagement is obtaining an employee's "emotional pockets share" to reap positive, lasting alternatives in an organization (Kumar \& Raghavendran, 2015). Gamification is additionally one of the equipment of worker engagement at the workplace. Notably, gamified connections are beneficial for tremendous remarks and further motivate workers essentially.

\section{Employee participation (BLUE WOLF IBM)}

IBM consulting firm Blue Wolf has pioneered a program called \#Going Social, with the help of Bunch ball's Nitro for retail staff solutions. By encouraging their staff to set out the public by placing "pack profiles." Their employees manage each profile, and they are getting rewards and cash incentives from the company. Along with the monetary benefits, employees also get some points when they reply on websites.

A retailing intensity consulting company, Blue Wolf, is working on a program referred to as '\#Going Social' with the assist of Bunch ball's Nitro for Salesforce solution. By encouraging their personnel to go Social via inserting 'pack profiles,' each profile is managed with the aid of their personnel. They are getting rewards and monetary incentives from the company. Along with the financial advantages, personnel additionally receive some factors when the reply on websites.

\section{Gamification in performance management}

The Conservative performance management system is time-ingesting and has a lack of transparency. So, the organizations favor changing from mundane and custom duties to exciting and enjoyable. Enduring leaders desired their performance management system to force social teamwork, gaining knowledge of and development, and cognizance of the employees. The answer integrated these features into a gamified platform for overall performance management that approves personnel to take part in customized studying prospects, enhance goal behaviors, and exhibit their accomplishments and abilities. EMee's evaluation system has been considered to compose the routine fun, all-encompassing, accessible, and visible. It steers non-stop overall 
performance management as a substitute for impounding assessments inside the usual end-ofyear event. It also lets any worker take part in a peer's comprehensive performance management, now not simply immediate team leaders an arrangement that allows in extra facts to be collected than is historically possible.

\section{Gamification can help to achieve sustainability}

Organizational sustainability requires people occupied, committed \& pleased, and is consequently required to take innovative new methods of doing stuff. Corporate sustainability has three noticeable sections, the Triple Bottom Line (TBL) being prevalent through Elkington in 2004. It is a system of bookkeeping and reporting composed of social, environmental, and monetary results.

\section{Gamification and sustainability}

Table 3 Gamification and sustainability

\begin{tabular}{|c|c|c|}
\hline S. No. & Authors & Sustainability Approaches \\
\hline $\mathbf{1}$ & (NegruÅŸa et al., 2015) & $\begin{array}{l}\text { Authors have suggested that gamification should } \\
\text { enhance sustainability efforts by taking an } \\
\text { inclusive approach towards the local community, } \\
\text { society, and resources. The authors mentioned the } \\
\text { need to improve the awareness of tourists } \\
\text { regarding sustainability using gamification. }\end{array}$ \\
\hline 2 & (Rozenfeld, 2018) & $\begin{array}{l}\text { This research paper underlines the need to explore } \\
\text { the possibilities of adopting gamification } \\
\text { techniques in the manufacturing industry. It } \\
\text { explored the various stages of the approach to } \\
\text { building sustainability. }\end{array}$ \\
\hline 3 & (J. et al., 2013) & $\begin{array}{l}\text { The paper discusses the need to bring } \\
\text { gamification to a healthy climate and } \\
\text { environment, social well-being, and economic } \\
\text { security. These are the factors that have been } \\
\text { considered crucial for getting sustainability into } \\
\text { society. }\end{array}$ \\
\hline 4 & (Russell-Bennett, 2021) & $\begin{array}{l}\text { This research focused on adopting gamification to } \\
\text { increase customer engagement and value-in-app } \\
\text { behavior to enhance sustainable energy behavior. } \\
\text { Gaming also increased positive perception } \\
\text { towards sustainability. }\end{array}$ \\
\hline 5 & (Fuchs, 2021) & $\begin{array}{l}\text { This research explores the use of games in } \\
\text { enhancing awareness about the need for } \\
\text { sustainable behavior. It argues that gamification } \\
\text { presents an excellent opportunity to understand } \\
\text { the options, limitations, and results of our } \\
\text { decisions in terms of sustainability. }\end{array}$ \\
\hline 6 & (Fernández, 2021) & $\begin{array}{l}\text { This study talks about the utility of gamification } \\
\text { in the field of natural hazards. Authors argue that } \\
\text { the use of games for training purposes makes the }\end{array}$ \\
\hline
\end{tabular}




\begin{tabular}{|l|l|l|}
\hline & & $\begin{array}{l}\text { attempts of prevention and control better for } \\
\text { environmentalists. }\end{array}$ \\
\hline $\mathbf{7}$ & (Spanellis, 2021) & $\begin{array}{l}\text { This book discusses the adoption of the } \\
\text { gamification approach towards making } \\
\text { sustainable efforts. The idea is to use various } \\
\text { game design elements and principles to bring } \\
\text { awareness and social change. }\end{array}$ \\
\hline
\end{tabular}

(Authors' Own)

\section{Results}

Gamification should enhance sustainability efforts by taking an inclusive approach towards the local community, society, and resources (NegruÅŸa et al., 2015). One of the studies argues that adopting gamification will increase customer engagement and value-in app behavior to enhance sustainable energy behavior (Russell-Bennett, 2021). There have been recommendations to use various game design elements and principles to bring awareness and, eventually, social change (Spanellis, 2021).

After the COVID-19 shutdown, a fine-grained strategy is required to reopen commercial enterprise and society to motivate humans to travel selectively. Governments and businesses worldwide are presently working on technological know-how options to track contacts between human beings who have examined positive for COVID-19 and to put in force quarantine for these humans (also for new arrivals to the country). These tools leverage a couple of vicinity monitoring technologies together with the triangulation of GPS, Bluetooth, and the telephone tower, amongst others.

\section{The proactive role of $\mathrm{HR}$}

- Gamification is changing lives:

Gamification has been proven to contain human beings and encourage them to alter behaviors. Especially Covid -19 period (Burke, 2012), humans are spending more excellent time with family, consuming healthful meals, and growing wholesome existence lifestyle which sooner or later beneficial for a worker to be always healthy. This will be useful for the organizations to see the well-being of employees.

- Gamification will put people in control:

Through gamification, personnel will spend the most time with devices and technological know-how, making them distance themselves from their colleagues. With these spreading of viruses can be curtailed. It would be motivating personnel to make wiser preference of assembly their buddies via Apps and social structures to some period.

- Manage risk and Reward:

To have low-risk employees control themselves to reduce the personal threat of getting COVID. It is better to have screening to discover high-medium-low threat people; based on that, HR can reward low-risk people by giving those badges or appreciation/ Fitness certificates. For this, organizations can keep their personalized health APPs \& Health codes, motivating them to observe private lockdown.

\section{Gamification is the Future of Sustainable Way}

Through investing time and money in virtual reality technology, companies will set themselves up for a prosperous and sustainable future. Incorporating sustainable growth objectives into your business functions and placing up an efficient shared method are two complex notions that 
demand a logical methodology (Huiban, 2019). To make sense of this uncertainty, a group of Japanese creative minds has merged the seventeen UN SDGs and the three columns of sustainability: economic values, social and environmental, which are imbibed into the incredibly shared structure to design the 2030 SDG Game. This game is an inventive and distinctive attempt to deal with issues around the world. In the game, players toil in sets to confer how the planet will reach or fail to achieve the sustainability targets of the UN by 2030 .

Samsung Electronics developed the Samsung Nation Web page as a vicinity for followers of Samsung to seem to be at new products, supply feedback, hang out, troubleshoot, and more (Palmer, 2012). When participants of the Samsung Nations complete these particular duties, they acquire points, release badges, and might also be positioned on a leader board. Customer-facing manufacturers such as Samsung have viewed an upward shove in time spent on site, generated with the aid of customers

Jive, a social business enterprise software firm, has commenced the introduction of 'Jive Social Intranet Solution.' The answer blends social elements and gamification characteristics, such as tasks, comments, and incentives in real-time, and combines with productiveness purposes and regular intranet capabilities. Common integration factors consist of SharePoint, MS Office and Outlook, phone features, and secrecy settings.

\section{Conclusion}

To build and promote a continuous learning culture among the employees, organizations are finding Gamification techniques. For this, HR managers are using challenging tasks like online games, leaderboards, Hackathons. So it involves creativity, fun, and collaboration. Gamification is also useful for talent acquisition and sharpens employees' skills throughout their career, enhancing their "learning quotient "and improving performance. Especially during Covid times, HR managers are monitoring employees Health, social and behavioral issues through gamification. Currently, there is a lot of demand for automation and collaboration in a remote working system. According to $\mathrm{PwC}$, a global professional services firm, gamification helps its employee's digital skills. Hence in the era of new normalcy, corporates are investing in the digital upskilling of their employees, which makes them create a "Digital WorkForce" for business sustainability in the long run

\section{Limitations of the study and Future Research}

The study is available on literature available to date as primary data could not be collected due to Covid 19 pandemic. A literature review approach is executed as it expands the horizon of proficiency in this field. The literature review is conducted as it augments the skyline of capability in this field, besides the paper endeavors to draw out the acts of gamification followed by organizations nowadays. The advantages of gamification are given in the paper so that associations not after this idea are likewise urged to do as such. The role of gamification towards sustainable growth of business functions is given towards the completion of the paper to make the organizations reexamine and urge them to execute this idea in their associations.

Future research could be conducted to analyze the impact of gamification tools on employees' job satisfaction and engagement and how managers of small firms can use gamification to enhance employee productivity leading to growth in organizational revenue. As the present study uses a literature review, a more detailed analysis could be conducted in the future based on information collected afresh from corporate employees and managers involved in implementing innovative ways of gamification. 


\section{References}

Agarwal, R. (2020). Prudent HR measures during and post COVID-19 scenario. [Online] Available at: https://www.peoplemattersglobal.com/article/strategic-hr/prudent-hr-measuresduring-and-post-covid-19-scenario-25572

[Accessed 4 April 2021].

Ashraf Saeed Elsafty, M. R. (2020). The Role of Human Resource Management Towards Employees Retention During Covid-19 Pandemic in Medical Supplies Sector - Egypt. Business and Management Studies, 6(2).

Ayedee, N., Kumar, A., Bhuttan, A., \& Shaikh, A. (2021). Role of Emotional Intelligence and Strategic Human Resource Management during COVID-19 Pandemic. Academy of Strategic Management Journal, Volume 20.

Burke, B. (2012). Gamification 2020: What Is the Future of Gamification?. [Online] Available at: https://www.gartner.com/en/documents/2226015/gamification-2020-what-is-thefuture-of-gamification-

[Accessed 4 April 2021].

Carnevale, J. B., \&. Hatak, I. (2020). Employee Adjustment and Well-Being in the Era of COVID-19: Implications. Journal of Business Research, Volume 116, pp. 183-187.

Christensen, C. M. (1997). The Innovator's Dilemma: When New Technologies Cause Great Firms to Fail. Boston: Harvard Business School Press.

Deol, T. (2020). Companies furlough employees amid Covid-19 crisis: What it means, how it differs from layofs. [Online] Available at: https://theprint.in/theprint-essential/companies-furlough-employees-amid-covid19-crisis-what-it-means-how-it-differs-from-lay-offs/394592/

[Accessed 4 April 2021].

Ërgle, D., \& Ludviga, I. (2018). Use of Gamification in Human Resource Management: Vilnius, LITHUANIA, VGTU Press.

Fernández, P., \& Moreno, M. C. (2021). Urban Sustainability and Natural Hazards Management; Designs Using Simulations.. Sustainability, 13(2), p. 649.

Ferreira A. T. (2017). Gamification in the Workplace: A Systematic Literature Review. Recent Advances in Information Systems and Technologies, p. 571.

Fuchs, A. P. (2021). Games and Gamification-New Instruments for Communicating Sustainability. The Sustainability Communication Reader: A Reflective Compendium. s.l.:Springer.

Hamouche, S. (2020). COVID-19 and employees' mental health: stressors, moderators and plan for organizational actions. Emerald Open Research, 2(15).

Huiban, E. (2019). How gamification can help us achieve the UN SDGs. [Online] Available at: https://www.ice.org.uk/news-and-insight/the-civil-engineer/june-2019/howgamification-help-achieve-un-sdgs

[Accessed 4 April 2021].

Lee, J. J. et al. (2013). Greenify: fostering sustainable communities via gamification. Paris, france, Association for Computing MachineryNew York, United States.

Kniffin, K. M., Narayanan, J., \& Anseel, F. (2021). COVID-19 and the workplace: Implications, issues, and insights for future research and action. American Psychologist, 76(1), pp. 63-77. 
Kumar, A., \& Ayedee, N. (2021). An Interconnection between COVID-19 and Climate Change Problem. Journal of Statistics and Management Systems , 24(2), pp. 1-21.

Kumar, A., Pujari, P., \& Gupta, N. (2021). Artificial Intelligence: Technology 4.0 as a solution for healthcare workers during COVID-19 pandemic. Acta Universitatis Bohemiae Meridionalis, 24(1), pp. 23-42.

Kumar, H., \& Raghavendran, S. (2015). Gamification, the finer art: fostering creativity and employee engagement. Journal of Business Strategy.

Law, A. (2018). Gamification is serious business. [Online]

Available at: https://www.thehindubusinessline.com/news/variety/gamification-is-seriousbusiness/article20612596.ece1

[Accessed 4 April 2021].

Lawande, D. N., Mohile, R., \& Datta, S. (2016). Gamification and Employee Engagement:

Theoretical Review on the Role of HR. [Online]

Available at: https://www.asmaindia.in/pdf/press/21-Gamification-and-Employee-

Engagement-Theoretical-Review-on-the-Role-of-HR.pdf

[Accessed 4 April 2021].

Majzun, Z. (2020). Leadership competencies and the essential role of human resource development in times of crisis: a response to Covid-19 pandemic. Human resource Development International, 23(4), pp. 380-394.

Marilyn, B. Y. (2021). A New Normal: The Changed Landscape of Human Resource Development in the Wake of COVID-19. Sage journals, 23(1).

McGuire, D., Germain, M. L., \& Reynolds, K. (2021). Reshaping HRD in Light of the COVID19 Pandemic: An Ethics of Care Approach.. Advances in Developing Human Resources, 23(1), pp. 26-40.

Meister, J. (2020). The Impact Of The Coronavirus On HR And The New Normal Of Work. [Online]

Available at: https://www.forbes.com/sites/jeannemeister/2020/03/31/the-impact-of-thecoronavirus-on-hr-and-the-new-normal-of-work/?sh=5d6c94042b60

[Accessed 4 April 2021].

NegruÅŸa, A. L., Toader, V., Soficäf, A., \& Rus, R. V. (2015). Exploring Gamification Techniques and Applications for Sustainable Tourism. Sustainability, 7(8), pp. 11160--11189.

Nenadić, S. (2019). Gamification in HR; applicability and its importance in recruitment and selection.

[Online]

Available at: https://repository.acmt.hr/islandora/object/acmt\%3A82/datastream/PDF/view [Accessed 4 April 2021].

Palmer, D. (2012). The engagement economy: How gamification is reshaping businesses. [Online]

Available at: https://www2.deloitte.com/us/en/insights/deloitte-review/issue-11/theengagement-economy-how-gamification-is-reshaping-businesses.html [Accessed 4 April 2021].

Ramesh, M. (2020). Coronavirus Outbreak: From origin to spread, who it affects and the factors that may halt its progress - a primer. [Online] Available at: https://www.firstpost.com/living/coronavirus-outbreak-from-origin-to-spreadwho-it-affects-and-the-factors-that-may-halt-its-progress-a-primer-8176561.html

[Accessed 4 April 2021]. 
Saha, D., D. (2017). Digitalizing human resoruces through gamification for employee engagement. ELK Asia Pacific Journals.

Shaikh, A., Kumar, A., Syed, A. A., \& Shaikh, M, Z. (2021). A Two-Decade Literature Review on Challenges Faced by SMEs in Technology Adoption. Academy of Marketing Studies Journal, 25(3).

Simpson, P. (2015). Gamification and Human Resources: an overview. Gamification and Human Resources: an overview.

Spanellis, A., \&. Harviainen, J. T. (2021). Transforming Society and Organizations through Gamification: From the Sustainable Development Goals to Inclusive Workplaces.. s.1.:Palgrave Macmillan.

Staff Writer, 2017. Gamification: A Game Changer for HR. [Online] Available at: https://www.hrtechnologist.com/articles/learning-development/gamification-agame-changer-for-hr/

[Accessed 4 April 2021].

Talview (2020). 6 Key Recruitment Challenges Amidst COVID-19. [Online]

Available at: https://blog.talview.com/6-key-recruitment-challenges-amidst-covid-19

[Accessed 4 April 2021].

Walls, P. J. (2021). Investing In Human Capital: Achieving Organizational Competitiveness Through Gamification.. ENDLESS: International Journal of Future Studies, 4(1), pp. 1-7.

Whittaker, L., Mulcahy, R., \& Russell-Bennett, R. (2021). 'Go with the flow'for gamification and sustainability marketing. International Journal of Information Management, 102305.

Zoe, E. (2019). Level up: How gamification in recruitment can attract top talent. [Online] Available at: https://www.efrontlearning.com/blog/2019/04/gamification-in-recruitmentattract-talent.html

[Accessed 4 April 2021]. 